Rev. Interd. em Cult. e Soc. (RICS), São Luís, v. 6, n. 1, p. 79- 91, jan./jun. 2020

ISSN eletrônico: 2447-6498

\title{
As Tranças de Ifemelu: a Migração e o Entre-lugar no Livro Americanah ${ }^{1}$
}

\author{
Ifemelu's Braids: Migration and In-between in the Book Americanah
}

\author{
CLARA CARDOSO FERREIRA COSTA \\ Mestre pelo Programa de Pós-Graduação em Cultura e Sociedade (UFMA) \\ clr.cfc@gmail.com
}

\section{RESUMO}

Em Americanah (ADICHIE, 2014), conhecemos Ifemelu, que se descobre nigeriana, imigrante, negra, escritora e mulher, assim que chega aos Estados Unidos e se depara com a necessidade de afirmar e encarar todas as identidades que, previamente, não precisou afirmar. Quinze anos depois, prepara-se para retornar à terra natal, receosa de ser vista como "americanah" (como os nigerianos chamam aqueles que retornam à Nigéria com trejeitos e sotaques estadunidenses). Nesse artigo, analisamos a migração, suas consequências nas identidades dos que se deslocam, as dificuldades no convívio com as diferenças culturais e conceitos como hibridismo e entre-lugar (BHABHA, 1998), a partir da história de Ifemelu. Portanto, faremos uma análise do livro e do desenvolvimento de suas personagens a partir da seguinte trança de conceitos: identidade, cultura, deslocamento, hibridismo e entre-lugar.

Palavras-chave: Americanah. Entre-lugar. Migração.

\begin{abstract}
In Americanah (ADICHIE, 2014), we meet Ifemelu, who discovers herself as a Nigerian, an immigrant, a black woman, a writer and a woman, as soon as she arrives at the United States of America and encounters all of the identities that she did not have to claim previously. Fifteen years later, she prepares herself to go back to her homeland, afraid to be seen as "americanah" (Nigerians use this term to call those who come back to Nigeria with American grimaces and accents). In this article, we analyze migration, its consequences in the identities of those who move, the difficulties they encounter while coexist among cultural differences and concepts as hybridism and in-between (BHABHA, 1998), after Ifemelu's story. Therefore, we will analyze the book and its characters' development after the following braid of concepts: identity, culture, displacement, hybridism and in-between.
\end{abstract}

Keywords: Americanah. In-between. Migration.

\section{INTRODUÇÃO}

Oscar Wilde (1854-1900), uma vez, escreveu que "o segredo da vida está na arte". Podemos questionar quem imita quem, a arte ou a vida ou ambas, quem sabe? O que nos é claro é que podemos compreender melhor uma a partir da outra e vice-versa. A relação entre o artista, a obra, sua inspiração, a realidade em que vive, o público e o eco derivado da arte é cíclica. Portanto, para realizar uma análise profunda sobre uma obra de arte, somos impelidos a pesquisar o universo maior em que ela foi feita e com o qual conversa.

\footnotetext{
${ }^{1}$ Artigo submetido para avaliação em 10/10/2019 e aprovado em 20/10/2019.
} 
Rev. Interd. em Cult. e Soc. (RICS), São Luís, v. 6, n. 1, p. 79- 91, jan./jun. 2020 ISSN eletrônico: 2447-6498

A obra aqui analisada, Americanah (ADICHIE, 2014), conta as histórias de Ifemelu e Obinze, namorados de infância que se separam quando migram da Nigéria para os Estados Unidos e para a Inglaterra, respectivamente, e as mudanças, dificuldades, felicidades, tristezas, enfim, o que acontece em suas vidas antes e depois do deslocamento. Incontáveis paralelos e análises podem ser feitos a partir de Americanah (ADICHIE, 2014), mas aqui entendemos o deslocamento migratório como ponto chave e principal conflito do livro. Tudo o que aparece como flashback antes do deslocamento é pano de fundo para entendermos o peso das coisas que acontecem depois que Ifemelu e Obinze (assim como outras personagens) emigram. Portanto, Americanah (ADICHIE, 2014) é aqui entendido como um romance diaspórico.

A partir das trajetórias das personagens, a escritora nigeriana Chimamanda Ngozi Adichie retrata a diáspora nigeriana em sua complexidade e diversidade de causas e consequências, assim como estampa a posição confusa e incerta a que o migrante se sujeita: o entre-lugar (BHABHA, 1998). O termo "entre-lugar" surgiu em meados dos anos 1970, com o brasileiro Silviano Santiago, modernista que, em sua pesquisa antropofágica, buscava entender o Brasil a partir de uma visão descentralizada e descentralizadora, capaz de alcançar a descolonização na clandestinidade, deslocandose de um único referencial de mundo, pautado no eurocentrismo.

O entre-lugar que aqui trataremos, que Bhabha também chama de espaço intersticial, é o intervalo, a transição, o lugar abstrato que o deslocado/migrante ocupa, pois suas identidades culturais e suas relações com as culturas também serão deslocadas e, depois da migração, mais do que nunca, estarão pautadas na diferença. O processo de identificação cultural acontece com mais nitidez não pelas vias das semelhanças, mas pelas diferenças que encontramos no processo de comparação entre nós e as outras pessoas (SILVA, 2014). Sei quem sou por saber quem não sou.

Ifemelu, cuja trajetória será nosso objeto de análise, só se descobriu negra, africana e imigrante ao chegar aos Estados Unidos. Até então, não fazia sentido pensar em si mesma como nigeriana, muito menos como africana, pois todos ao seu redor também o eram. Também não pensava em raça, pois, como ela mesma coloca, na Nigéria, essa não era uma questão. Foi só quando ela se percebeu estrangeira, inclusive no sentido de ser uma "estranha", que ela começou a refletir e a sentir as diferenças culturais e identitárias que a caracterizavam. 
Rev. Interd. em Cult. e Soc. (RICS), São Luís, v. 6, n. 1, p. 79- 91, jan./jun. 2020 ISSN eletrônico: 2447-6498

Nesse artigo, debruçar-nos-emos sobre a sua movimentação entre Nigéria e Estados Unidos e nas suas experiências vividas nos dois países, na ida para os Estados Unidos e no retorno para a Nigéria, para investigarmos, a partir de sua história, conceitos como: entre-lugar, hibridismo, identidade, cultura e deslocamento. Enquanto Ifemelu trança os cabelos, trançaremos também suas identidades e seus lugares.

\section{A DIÁSPORA NIGERIANA EM AMERICANAH}

O fascínio pelo país estrangeiro mais desenvolvido, muitas vezes pintado como um paraíso onde sonhos se realizam, onde é possível ter uma vida melhor do que a que seu país de origem podem ofertar, é uma realidade, principalmente, para países subdesenvolvidos ou em desenvolvimento (SILVA, 2006), que retrata as consequências de séculos de exploração, colonização, imperialismo, domínio de países mais ricos sobre países mais pobres (domínio, inclusive, cultural), ou seja, das desiguais relações de poder que permeiam a história da humanidade. Segundo Fiori (2010, p. 134), já desde o século XII, é possível perceber que, “(...) no universo dos poderes soberanos que se formaram na Europa, a acumulação do poder foi sempre uma necessidade inevitável, permanente e absoluta".

Ao longo da História, os processos migratórios tiveram diferentes motivações e consequências. Se nos voltarmos às Grandes Navegações, por exemplo, encontramos por um lado os europeus, que saíam de seus países em busca de riquezas e conquistas, por outro lado, os africanos do Leste da África, escravizados e vendidos como mercadoria em um esquema de tráfico humano, e, por outro lado, os povos nativos das terras "descobertas" pela exploração europeia, que perderam suas terras e suas vidas como consequência da invasão. Poderíamos incluir, na seguinte afirmação: “O passado escravagista e colonial da África não tem o mesmo significado para africanos e europeus" (HUGON, 2009, p. 12), todos os países e povos que já foram colonizados e seus colonizadores. São duas experiências completamente diferentes e que deixam marcas também muito distintas:

O processo migratório, envolvendo rupturas espaciais e temporais, transformações diversas, nomeadamente mudanças psicológicas, ambientais, biológicas, sociais, culturais, familiares, políticas, implicando a adaptação psicológica e social dos indivíduos e das famílias e diferentes modalidades de aculturação, constitui um processo complexo, com consequências ao nível do desenvolvimento individual, sócio-profissional e da saúde física e psíquica. A migração não implica apenas a deslocação espacial e não é, simplesmente, sinónimo de encontro cultural. Implica uma adaptação à cultura de 
Rev. Interd. em Cult. e Soc. (RICS), São Luís, v. 6, n. 1, p. 79- 91, jan./jun. 2020 ISSN eletrônico: $2447-6498$

acolhimento, a um meio novo, desconhecido ou hostil. Constitui um processo complexo, contraditório, uma experiência de perda, ruptura, mudança, vivenciada pelo indivíduo de uma forma mais ou menos traumatizante ou harmoniosa, segundo os seus recursos psicológicos e sociais, as características da sociedade dominante, as condições de acolhimento e as políticas do país receptor. (RAMOS, 2009, p. 5)

Em Americanah (ADICHIE, 2014), encontramos uma Nigéria assolada por um regime militar autoritário e perverso, em que as perversas desigualdades socioeconômicas e as precárias condições de vida motivam centenas de nigerianos a migrar, subitamente, em busca de melhores perspectivas para seus futuros e/ou melhores condições de vida já em seus presentes. Embora Ifemelu, a personagem principal do romance, tivesse sonhos e planos com seu namorado de futuramente irem para os Estados Unidos, o que realmente a levou a fazê-lo foi a decadência das universidades e, por consequência, das possibilidades de um futuro melhor em seu país natal.

O sonho de morar no exterior era comum entre as pessoas de seu convívio e até mesmo uma possibilidade muito mais concreta, em alguns casos, como o de Kayode, cujos pais tinham uma casa na Inglaterra, onde o garoto passava todas as suas férias. A namorada dele, Yinka, também ia com frequência à Grã-Bretanha e falava inglês com sotaque britânico, exibindo, assim, "ares de outro lugar".

Mesmo os que não tinham as mesmas condições acreditavam que, nos Estados Unidos e na Inglaterra (esses são os países que mais aparecem nas falas), a vida é melhor. A exemplo: os pais de Ginika², professores universitários já insatisfeitos com o regime militar e as péssimas condições de trabalho, decidiram abandonar a vida na Nigéria e recomeçar nos Estados Unidos. Já o colega de turma Emenike era fascinado por qualquer pessoa que fosse para o exterior. Eventualmente, por meios um tanto obscuros, conseguiu um visto para a Inglaterra e lá se estabeleceu. Um poema fez Obinze, namorado de Ifemelu, querer estudar nos Estados Unidos e, embora Ifemelu priorizasse a Inglaterra aos Estados Unidos, foi o fascínio e o apoio dele que mais influenciaram sua decisão de pleitear uma bolsa e estudar em uma universidade estadunidense.

Embora, aparentemente, as motivações pessoais das personagens para a migração sejam diversas e se mostrem subjetivas, o que podemos perceber, no livro, é

\footnotetext{
${ }^{2}$ A primeira vez que o termo "americanah" aparece no romance é durante a despedida de Ginika, quando Ranyinudo, amiga dela e de Ifemelu, prevê que a América afetará Ginika a ponto de ela entrar em outra categoria, a da pessoa que sai da Nigéria e volta "afetada" pelas culturas dos lugares para onde foi.
} 
Rev. Interd. em Cult. e Soc. (RICS), São Luís, v. 6, n. 1, p. 79- 91, jan./jun. 2020 ISSN eletrônico: $2447-6498$

que, seja com planejamento longo e prévio, seja por proposta de emprego, seja por terem familiares em outros países que facilitariam a adaptação e os processos legais, o motivo central que leva todas as personagens a deixarem a Nigéria é o mesmo: a pobreza e a decadência exponencial das condições de vida e trabalho, consequentes do regime ditatorial vigente.

No volume 7 do Caderno de Debates Refúgio, Migrações e Cidadania (2012), organizado pelo Instituto Migrações e Direitos Humanos (IMDH), encontramos a transcrição da exposição de Paulo Sérgio de Almeida, presidente do Conselho Nacional de Imigração, que diz:

[...] as origens são muitas vezes as mesmas: estão fundadas na pobreza, na exclusão social, no desemprego e na falta de oportunidades, além das desigualdades entre países e regiões. Todos esses fatores estão tanto na origem dos fluxos migratórios, nos quais as pessoas buscam na migração opções de sobrevivência e de uma vida com mais dignidade, quanto na vulnerabilidade das pessoas que facilita seu aliciamento pelos traficantes. Aliás, a pobreza torna, em muitos casos, a migração mais do que uma simples opção pessoal. Para muitas pessoas a migração é uma necessidade, constitui uma estratégia de sobrevivência [...]. (ALMEIDA, 2012, p. 44)

Em um planejamento improvisado e arquitetado quase que às pressas, Ifemelu sai de seu país natal para se aventurar nos Estados Unidos da América, onde já chega com a consciência de que terá de infringir as leis para conseguir trabalhar, pois seu visto a limita a ser apenas estudante. Além do notório problema legal, ela não chega com muito dinheiro, não tem real noção de como a sociedade estadunidense vive e sua tia e sua amiga, que a ajudam, moram muito longe do campus da universidade, o que a leva a procurar moradia muito rapidamente e sem poder colocar muitos critérios. Bastou pisar nos Estados Unidos para começarem os problemas de adaptação.

Apesar de todas as dificuldades enfrentadas durante a adaptação, o pensamento comum é que, uma vez estabelecida a vida fora, esses migrantes não voltarão à Nigéria, portanto devem fazer o máximo possível para se organizarem rapidamente nos novos lugares. Treze anos depois, quando essas questões práticas não são mais um problema para ela (diferentemente da experiência de Obinze em terras britânicas), consegue reconhecer migrantes africanos quase que apenas pelo olhar. Em geral, são mão-de-obra barata e lutam para se manter na terra do Tio Sam, trabalhando em obras, táxis, shoppings, salões de beleza, "casas de família", etc. Exatamente o mesmo leque de oportunidades que Ifemelu encontrara em sua chegada, antes de conseguir um visto, um diploma e bons contatos. 
Rev. Interd. em Cult. e Soc. (RICS), São Luís, v. 6, n. 1, p. 79- 91, jan./jun. 2020 ISSN eletrônico: $2447-6498$

O romance retrata todos os migrantes, mesmo os mais adaptados, exatamente como o são: estrangeiros. Pessoas que carregam outros lugares, outras culturas, outros mundos consigo, que, como Ifemelu, não entendem a importância da discussão da raça para a sociedade americana, por não ser uma preocupação em seus lugares de origem. Pessoas que se contentam, ou se misturam, ou tentam perder seus sotaques, ou perdem sem querer, ou sentem falta de casa, ou não querem voltar por nada nesse mundo. Pessoas que reconhecem facilmente outras pessoas que estão na mesma condição: pessoas deslocadas (SAID, 2003).

O deslocamento, segundo Edward Said (2003, p. 58), ressalta uma verdade antes despercebida: "damos como certas a pátria e a língua, elas se tornam natureza, e seus pressupostos subjacentes retrocedem para o dogma e a ortodoxia”. O migrante é o sujeito que perde o contato direto com sua pátria e, muitas vezes, com sua língua. Ele precisa se reinserir em uma sociedade que não conhece, cujos membros se comunicam e performatizam suas identidades e culturas de modo diferente do seu, cujas narrativas de vida, de ser e estar no mundo têm outras estruturas (BOURDIEU, 1996; RICOEUR, 1994). O deslocado é o sujeito que não consegue se integrar completamente (às vezes, nem parcialmente) a um grupo.

O migrante, quem realiza um deslocamento concreto e radical, por mais que se adapte, nunca terá a mesma visão ou a mesma experiência que os sujeitos que nasceram e cresceram naquele lugar. De mesmo modo, não acompanhará seu país natal do mesmo jeito que aqueles que ficaram. Ele não está mais nem cá, nem lá; ele está na transição ou no interstício ou no entre-lugar (BHABHA, 1998). Esse é o estranho fenômeno em que Ifemelu se encontra assim que migra pela primeira vez.

Podemos distinguir dois períodos-chave em que o entre-lugar é demonstrado com clareza na narrativa: quando Ifemelu chega aos EUA e não se reconhece ali, nem mesmo nos adjetivos que usam para descrevê-la: negra, africana, exótica, estranha; e quando ela retorna, finalmente, à Nigéria, e não consegue se readaptar de imediato. $\mathrm{O}$ sol, a pressa no trânsito, o suor, a desordem humana nas movimentações nas ruas, as pilhas de lixo na beira da estrada, a densidade do ar, o comércio, a vida em Lagos é tão diferente com o que ela se acostumara nos últimos treze anos que mais parece uma agressão a seus sentidos. De mesmo modo, os Estados Unidos também lhe foram agressivos à primeira vista. Como Narciso, Ifemelu achou feio o que não era espelho. As diferenças culturais, explicitadas por sua condição de deslocada, induziram-na a uma 
Rev. Interd. em Cult. e Soc. (RICS), São Luís, v. 6, n. 1, p. 79- 91, jan./jun. 2020

ISSN eletrônico: 2447-6498

adaptação maior e mais profunda do que esperava, fazendo com que até mesmo suas identidades precisassem mudar, como veremos em seguida.

\section{LUGARES, HIBRIDISMO E AS IDENTIDADES DE IFEMELU}

É importante salientar que os lugares, em Americanah (ADICHIE, 2014), estão dotados de valores de acordo com experiências, relações, vontades, sonhos, imaginários e culturas ali vividos ou idealizados pelas personagens. A Inglaterra vivida por Obinze é opressora, aterrorizante, incerta e humilhante. A Inglaterra vivida por Emenike é próspera, estável e propícia à ascensão social. De mesmo modo, os Estados Unidos, para Ifemelu, vão adotando e abandonando características ao longo de sua adaptação ao lugar, assim como a Nigéria se torna, treze anos depois da sua partida, o lugar desejado, onde ela poderia fincar suas raízes e pertencer. Portanto, há um caráter topofílico (TUAN, 2012) nos lugares apresentados no romance.

Para o geógrafo humanista Yi-Fu Tuan (2012, p. 19), "Topofilia é o elo afetivo entre a pessoa e o lugar ou ambiente físico. Difuso como conceito, vivido e concreto como experiência pessoal [...]". As descrições físicas dos lugares, no romance, são menos importantes do que o que aqueles lugares causam nas personagens, sejam efeitos positivos ou negativos. Não aprenderemos sobre as ruas da Filadélfia, mas saberemos como Ifemelu se sentiu ao navegar por elas. O que nos importa não é a disposição dos produtos nas prateleiras dos supermercados estadunidenses, mas o estranhamento que a personagem sentiu ao ver todos aqueles produtos industrializados, as promoções, as refeições criadas com esses produtos, os hábitos culinários do país, tão diferentes dos seus, ou seja, o choque cultural que ela sentiu ao chegar àquele lugar e como ela se adaptou (ou não) a ele. Aqui, fazemos a distinção da experiência de Ifemelu e a de outras duas nigerianas com quem manteve contato direto: tia Uju e Ginika.

\footnotetext{
Para compreender a preferência ambiental de uma pessoa, necessitaríamos examinar sua herança biológica, criação, educação, trabalho e os arredores físicos. No nível de atitudes e preferências do grupo, é necessário conhecer a história cultural e a experiência de um grupo no contexto de seu ambiente físico. (TUAN, 2012, p. 91)
}

O primeiro choque entre expectativa e realidade vem na figura de tia Uju, cuja situação financeira, antes tão abastada e confortável na Nigéria, agora se mostra tão precária quanto a de Ifemelu. Antes uma mulher sofisticada, acostumada a regalias e conforto, agora trabalha em três empregos diferentes, luta para validar seu diploma 
Rev. Interd. em Cult. e Soc. (RICS), São Luís, v. 6, n. 1, p. 79- 91, jan./jun. 2020 ISSN eletrônico: 2447-6498

como médica e consome sempre o produto mais barato do mercado. Aos olhos de Ifemelu, tia Uju adotou uma postura de completa subserviência aos Estados Unidos. Ela se vê como inferior. Não fica claro se ela se sente inferior aos americanos, mas se sente inferiorizada com relação a quem era e à vida que levava na Nigéria.

Tia Uju se tornou uma pessoa "seca". Não mais se preocupa com beleza e vaidade, irrita-se com facilidade, mantém um nível alto e constante de estresse e trata as dúvidas de Ifemelu sobre os Estados Unidos como se fossem tolices, cujas respostas deveriam ser óbvias. A amargura de tia Uju está completamente relacionada a seu luto pelo namorado assassinado na Nigéria e pela vida confortável e cheia de perspectivas que perdera. Contudo, o que queremos ressaltar aqui é a forma com a qual a personagem se adaptou ao país estrangeiro: tornando-se quase invisível, rebaixava-se, aceitando tudo que lhe fosse imposto e renegando propositalmente muitas marcas culturais de sua terra natal.

Ifemelu se recusa a agir como tia Uju, mas também não consegue se adaptar com tanta facilidade quanto Ginika, sua amiga de infância, quem, a essa altura, já morava nos Estados Unidos havia anos, consolidara um grupo de amigas e se familiarizara com os costumes estadunidenses. Ela emagrece, pois, nos Estados Unidos, ser gorda é uma ofensa. Fala gírias nigerianas obsoletas, pois seu linguajar ficou parado no momento da partida. Por não viver mais na Nigéria, não consegue acompanhar a dinâmica da língua que, antes, era sua. Agora, ela ensina Ifemelu o que faz e o que não faz sentido falar, de acordo com as gírias americanas e chama a si própria de birracial (aprendeu que deve se ofender se alguém a chamar de mestiça). Ela dominava os códigos e as maneiras de ser: absorvera as culturas estadunidenses.

Tia Uju e Ginika são os dois primeiros exemplos de "americanah's" que encontramos. O título jocoso "americanah" se refere a quem absorve aspectos culturais dos lugares para onde migraram, ou seja, a quem se torna híbrido. Há uma ligação entre hibridismo e entre-lugar, mas, antes, esclareçamos o que cada uma das coisas significa. Primeiro, façamos o discernimento entre híbrido e hibridismo.

O híbrido, resultado da hibridação cultural, é resultado de "uma componente intrínseca à sociedade democrática e plural" (CARNEIRO, 2006, p. 40). De acordo com Carneiro (2006), como consequência do fenômeno da globalização, a miscigenação de culturas antes muito distanciadas gerou o sujeito cultural híbrido, alimentado pela vida em rede (CASTELLS, 2000). A sociedade contemporânea, cada vez mais entrelaçada 
Rev. Interd. em Cult. e Soc. (RICS), São Luís, v. 6, n. 1, p. 79- 91, jan./jun. 2020

ISSN eletrônico: $2447-6498$

em uma teia de informações, comunicações instantâneas e contato virtual, quebra as fronteiras físicas previamente limitantes. A hibridação seria uma consequência da globalização não necessariamente imposta ou conflitante (embora cultura seja, também, conflito). Essa visão do híbrido é muito mais suave, embora potente, do que a entendida por Homi K. Bhabha (1998) como resultante do hibridismo cultural.

Para Bhabha (1998), a prioridade é o conflito. Enquanto Garcia Canclini (2003) e Carneiro (2006) analisam o híbrido cultural como uma consequência inevitável do processo de globalização, Bhabha (1998) estuda esse fenômeno sob a ótica não da globalização, mas do colonialismo e do pós-colonialismo. Ou seja, são momentos históricos diferentes, embora ligados. Ao analisar os efeitos da colonização indiana pela Inglaterra, Bhabha (1998) percebeu mudanças culturais resultantes da absorção de marcas culturais impostas pela metrópole como sendo as corretas, civilizadas e ideais. Como de acordo com uma visão etnocêntrica, a Inglaterra era o modelo a se seguir, pois estava no "centro do mundo" (TUAN, 2012, p. 55).

Portanto, o hibridismo seria um processo de conflito constante entre culturas. Por um lado, temos o opressor, dotado de um aparato ideológico e material que lhe concede poder, e, por outro lado, o oprimido, cujas culturas se tornam, de um dia para o outro, símbolo de resistência cultural. As culturas do colonizador são incorporadas pelo colonizado à força, não somente por sua presença, como pela ideologia civilizatória e eurocêntrica disseminada durante aquela época. O hibridismo tem como seu fundamento os conflitos, as relações de poder existentes entre diferentes culturas e a dominação de umas sobre as outras:

A articulação social da diferença, da perspectiva da minoria, é uma negociação complexa, em andamento, que procura conferir autoridade aos hibridismos culturais que emergem em momentos de transformação histórica. [...] Os embates de fronteira acerca da diferença cultural têm tanta possibilidade de serem consensuais quanto conflituosos; podem confundir nossas definições de tradição e modernidade, realinhar as fronteiras habituais entre o público e o privado, o alto e o baixo, assim como desafiar as expectativas normativas de desenvolvimento e progresso. (BHABHA, 1998, p. 21)

Trazemos a discussão do que é o hibridismo e as consequências do colonialismo por entendermos que falar sobre a história dos países africanos após a chegada dos europeus e a consequente migração forçada desses povos reflete nos processos migratórios atuais. A ideologia de que a Europa e, agora, também, os Estados Unidos são inerentemente melhores, provedores de maior qualidade de vida, donos de 
Rev. Interd. em Cult. e Soc. (RICS), São Luís, v. 6, n. 1, p. 79- 91, jan./jun. 2020 ISSN eletrônico: 2447-6498

culturas superiores persiste até hoje e pode ser encontrada, inclusive, no romance aqui estudado:

As identidades formadas no interior da matriz dos significados coloniais foram construídas de tal forma a barrar e rejeitar o engajamento com as histórias reais de nossa sociedade ou de suas "rotas" culturais. Os enormes esforços empreendidos, através dos anos, não apenas por estudiosos da academia, mas pelos próprios praticantes da cultura, de juntar ao presente essas "rotas" fragmentárias, freqüentemente ilegais, e reconstruir suas genealogias não-ditas, constituem a preparação do terreno histórico de que precisamos para conferir sentido à matriz interpretativa e às auto-imagens de nossa cultura, para tornar o invisível visível. (p. 42)

Já no primeiro capítulo do livro, quando Ifemelu informa as pessoas de seu desejo de retornar à Nigéria, movimento que ela acredita imprescindível para se sentir completa novamente, ninguém a entende. A ideia de que a vida nos Estados Unidos é preferível à vida na Nigéria está tão incrustada no senso comum que as pessoas estranham que uma nigeriana queira voltar para sua terra natal, principalmente por Ifemelu ter uma vida confortável, estável e legalizada nos EUA. A Nigéria seria um lugar para deixar para trás, não para retornar; contudo, para Ifemelu, o país de origem voltou a ser o seu lugar:

No entanto, tinha cimento na alma. Estava lá havia algum tempo, numa fadiga matutina, algo sombrio e sem contornos nítidos. E trouxe consigo anseios amorfos, desejos indistintos, vislumbres breves e imaginários de outras vidas que ela poderia estar vivendo, que ao longo dos meses se transformaram numa lancinante saudade de seu país. Ifemelu lia avidamente sites nigerianos, perfis nigerianos no Facebook, blogs nigerianos, e cada clique levava a mais uma história de um jovem que havia pouco voltara para casa, brandindo diplomas americanos ou britânicos, para fundar uma financeira, uma produtora de música, uma marca de roupas, uma revista, uma rede de fast-food. Ela olhava para as fotos desses homens e mulheres e sentia uma dor surda de perda, como se tivessem aberto sua mão à força e pegado algo que lhe pertencia. Eles estavam vivendo a vida dela. A Nigéria passou a ser o lugar onde Ifemelu deveria estar, o único lugar onde poderia fincar suas raízes sem sentir a vontade constante de arrancá-las de novo e sacudir a terra. (ADICHIE, 2014, p. 13)

É o efeito ideológico do poder do capital simbólico, para além do poder material, que garante a impregnação no senso comum de uma relação de inferioridade e superioridade entre culturas, baseada, muitas vezes, no capital econômico (BOURDIEU, 2002). A Nigéria, nesse sentido, embora não seja literalmente uma colônia estadunidense ou inglesa no período em que o romance se passa, demonstra os efeitos do hibridismo, herdados da colonização, como o fato de sua língua oficial não ser nenhum dos dialetos nativos, mas a língua inglesa. De mesmo modo, percebemos 
Rev. Interd. em Cult. e Soc. (RICS), São Luís, v. 6, n. 1, p. 79- 91, jan./jun. 2020 ISSN eletrônico: $2447-6498$

claramente a ideologia etnocêntrica que cria a ilusão da superioridade de países como os Estados Unidos e a Inglaterra, meramente por serem países mais "desenvolvidos":

É enquanto instrumentos estruturados e estruturantes de comunicação e de conhecimento que os sistemas simbólicos cumprem a sua função política de instrumentos de imposição ou de legitimação da dominação, que contribuem para assegurar a dominação de uma classe sobre outra (violência simbólica) dando o reforço da sua própria força às relações de força que a fundamentam e contribuindo assim, segundo a expressão de Weber, para a domesticação dos dominados. (BOURDIEU, 2002, p. 11)

Ifemelu observa, tanto em sua chegada aos Estados Unidos como no fim de sua experiência por lá, as discrepâncias entre as culturas e o que é esperado de cada um. Pela primeira vez, ela se percebe como a alheia, a estranha, a estrangeira. Todas as suas ações, como o fato de não querer tocar em um cachorro, repentinamente, são questionadas não como algo pessoal, mas cultural. Tudo vira diferença cultural, tudo é estranhamento, tanto para ela quanto para as pessoas que interagem com ela.

Ela estranha desde o hábito de dar gorjetas para garçons até o racismo sistêmico, o qual a induz a criar, futuramente, um blog sobre raça e outras questões sociais. Ela não se identifica com eles, pois as identidades com a qual se identifica são outras. Nesse primeiro momento, ela ainda tem as identidades desenvolvidas na Nigéria como as suas verdadeiras. É a partir dessas identidades que não apenas ela se reconhece como também reconhece o mundo em que vive (HALL, 2011).

Nos Estados Unidos, ela acabará adotando outras identidades: mulher, negra, africana, estrangeira e, sem perceber, americanah. A primeira surge em decorrência tanto de seu crescimento e do passar dos anos, como das diferentes situações em que percebe a diferença entre ser mulher e ser homem nas sociedades nigeriana e estadunidense. A segunda, a terceira e a quarta lhe são impostas como decorrência do deslocamento migratório e das estruturas sociais americanas. A última, que vai surgindo gradualmente, só é realmente percebida em seu retorno à Nigéria. Suas identidades, intrinsecamente conectadas às culturas, aos lugares e às pessoas com quem convive, ditam suas experiências e são o ponto de partida de sua narrativa de vida.

\section{CONSIDERAÇÕES FINAIS}

Stuart Hall (2011, p. 27) afirma que, "na situação da diáspora, as identidades se tornam múltiplas". Ifemelu, em sua trajetória, demonstra exatamente isso: a multiplicidade das identidades e a importância da diferença no processo de 
Rev. Interd. em Cult. e Soc. (RICS), São Luís, v. 6, n. 1, p. 79- 91, jan./jun. 2020

ISSN eletrônico: 2447-6498

identificação e negação de tais identidades e culturas (SILVA, 2014). Ela navega entre lugares, culturas e identidades para nos mostrar o que significa estar em casa, seja no lugar de origem, seja nos outros lugares. São suas identidades mutáveis, plurais e contraditórias que nos permitem entender o que foi sua dupla experiência como migrante e as consequências que esse deslocamento pode suscitar.

Com seu espanto, entendemos o que é choque cultural. Com sua aflição, visualizamos as dificuldades que o deslocado enfrenta para realizar as tarefas mais mundanas. Com sua relutância em se submeter à sociedade americana, como tia Uju o fez, e em perder seu sotaque, encontramos resistência. Em sua solidão e angústia, vislumbramos a difícil realidade de quem é alheio, estranho, estrangeiro.

A última coisa significativa que Ifemelu faz, nos Estados Unidos, é trançar seus cabelos. Em um salão cujas dona e funcionárias também são migrantes, ela passa oito horas se preparando para voltar para a Nigéria. Enquanto observa aquelas mulheres, reflete sobre sua vida nos últimos anos, sobre o "cimento na alma" que a impeliu a retornar à terra natal, mas, principalmente, sobre como essa nova mudança trazia um futuro tão desconhecido para ela quanto a primeira.

Quando, finalmente, retorna, mais um choque. As ruas mudaram. Os celulares mudaram. Os pontos de ônibus mudaram. A língua mudou. Todavia, além dessas mudanças inevitáveis e previsíveis, a percepção de Ifemelu também mudou. Como sua amiga Ranyinudo, a primeira a lhe dar boas-vindas, afirma, ela está vendo a Nigéria com olhos de americano. Ifemelu está americanah e nem mesmo o percebeu, pois, nos Estados Unidos, não se sentia assim e lutou conscientemente para não perder seu sotaque nem os traços culturais da terra natal. Mesmo depois de se readaptar e ter a certeza de que se reencontrara ali, sua experiência no exterior influencia e continuará influenciando sua visão de mundo e sua vida. Uma vez no entre-lugar, as fronteiras se borram, os pertencimentos se esticam e a visão de mundo, antes muito definida, expande-se. Ela é agora sujeito do mundo. É americanah.

\section{REFERÊNCIAS}

ADICHIE, Chimamanda Ngozi. Americanah. Tradução: Julia Romeu. 1.ed. São Paulo: Companhia das Letras, 2014.

BHABHA, Homi K. O local da cultura. Tradução de Myriam Ávila, Eliana Lourenço de Lima Reis e Gláucia Renate Gonçalves. 1. ed. Belo Horizonte: Editora UFMG, 1998. 
Rev. Interd. em Cult. e Soc. (RICS), São Luís, v. 6, n. 1, p. 79- 91, jan./jun. 2020 ISSN eletrônico: 2447-6498

BOURDIEU, Pierre. A ilusão biográfica. In: FERREIRA, Marieta de M.; AMADO, Janaina (Org.). Usos \& abusos da história oral. Rio de Janeiro: FGV Editora, 1996.

. O poder simbólico. Rio de Janeiro: Bertrand Brasil, 2002.

CARNEIRO, Roberto. Hibridação e aventura humana. In: Comunicação \& Cultura. n.1, pp. 37-55, 2006. Disponível em:

<https://repositorio.ucp.pt/handle/10400.14/10361> Acesso em 16 de julho de 2019.

CASTELLS, Manuel. A sociedade em rede. São Paulo: Paz e Terra, 2000.

FIORI, José Luís da Costa. Prefácio ao poder global. In: Revista Tempo do Mundo (internet), v. 2, n.1, pp. 131-153, abr. 2010. Disponível em:

<http://www.ipea.gov.br/portal/images/stories/PDFs/rtm/100923_rtm_port02_cap6.pdf

$>$ Acesso em 16 de julho de 2019.

GARCIA CANCLINI, Néstor. Culturas Híbridas: Estratégias para Entrar e Sair da Modernidade. Tradução: Heloísa Pezza Cintrão, Ana Regina Lessa. São Paulo: Editora da Universidade de São Paulo, 2003.

HALL, Stuart. Da diáspora - identidades e mediações culturais. 1 ed. Tradução:

Adelaine La Guardia Resende, Ana Carolina Escosteguy, Cláudia Álvares, Francisco Rüdiger, Sayonaram Amaral. Belo Horizonte: Editora UFMG, 2011.

HUGON, Philippe. Geopolítica da África. Tradução: Constância Morel. Rio de Janeiro: Editora FGV, 2009.

RAMOS, Natália. Saúde, migração e direitos humanos. In: Revista Mudanças Psicologia da Saúde, v. 17, n. 1, pp. 1-11, jan./jun. 2009.

SAID, Edward. Reflexões sobre o exílio e outros ensaios. Tradução de Pedro Maria Soares. São Paulo: Companhia das Letras, 2003.

SILVA, S. A. Bolivianos em São Paulo: entre o sonho e a realidade. In: Estud. av., São Paulo, v. 20, n. 57, pp. 157-170, Aug. 2006. Disponível em:

$<$ http://www.scielo.br/scielo.php?script=sci_arttext\&pid=S0103-

$40142006000200012 \& \operatorname{lng}=\mathrm{en} \& n r m=$ iso>. Acesso em 15 de julho de 2019.

SILVA, Tomaz Tadeu da. Identidade e diferença: a perspectiva dos estudos culturais. Tomaz Tadeu da Silva (org.). Stuart hall, Kathryn Woodward. 15. ed. Petrópolis: Vozes, 2014.

TUAN, Yi-Fu. Topofilia: um estudo da percepção, atitudes e valores do meio ambiente. Tradução: Lívia de Oliveira. Londrina: Eduel, 2012. 